\title{
MALIGNANT CHONDROID SYRINGOMA IN THE ANTERIOR ABDOMINAL WALL: A RARE CASE REPORT
}

Ram Krishna Mondal ${ }^{1}$, Santanu Acharyya ${ }^{2}$, Debkumar Ray ${ }^{3}$, Sumitava De ${ }^{4}$

\section{HOW TO CITE THIS ARTICLE:}

Ram Krishna Mondal, Santanu Acharyya, Debkumar Ray, Sumitava De. "Malignant chondroid Syringoma in the anterior abdominal wall: a rare case report". Journal of Evolution of Medical and Dental Sciences 2013; Vol2, Issue 29, July 22; Page: 5402-5406.

ABSTRACT: Malignant chondroid syringomas (MCS), which are also called malignant mixed tumors of the skin, are extremely uncommon tumor arising from the eccrine sweat glands with tumor differentiation in the epithelial and mesenchymal tissues. Malignant chondroid syringomas commonly involve the limbs, head and neck rarely trunk. In this article, we present a case of malignant chondroid syringoma localized in the anterior abdominal wall. Wide local excision was followed by close observation. After 3 years of close observation the patient remains asymptomatic.MCS is rare with 43 reported cases in the literature. The site of the primary tumor was the lower extremity in 35 percent, the head in 28 percent, and the upper extremity in 23 percent .As MCS may progress very slowly and disease recurrence including metastasis occurs in a relatively high percentage of cases, long-term follow-up of MCS cases is required.

INTRODUCTION: Chondroid syringomas (CSs) are rare, benign tumors of the skin. In 1859, Billroth first described them as a mixed tumor of the skin due to its histopathological resemblance to the benign mixed tumor originating from salivary gland. ${ }^{[1,2]}$ The term "chondroid Syringoma" in lieu of mixed tumor of the skin was introduced by Hirsch and Helwig in 1961. They proposed the following microscopic diagnostic criteria: (a) Nests of cuboidal or polygonal cells; (b) Intercommunicating tubuloalveolar structures lined with two or more rows of cuboidal cells; (c) Ductal structures composed of one or two rows of cuboidal cells; (d) Occasional keratinous cysts; (e) A matrix of varying composition in hematoxylin and eosin stain. ${ }^{[3]}$ In 1961, Headington divided CS into two groups, including apocrine type and eccrine type, based on their histopathological appearance. [4] Chondroid syringomas most commonly occur in the head and neck with a size ranging from $2 \mathrm{~mm}$ to $\geq 1 \mathrm{~cm}$ and usually present with solitary, solid, painless, nonulcerative, subcutaneous, or intracutaneous nodule. ${ }^{[5,6]}$ They often affect middle-age to elderly patients with a male-to-female ratio of 2: 1 [6-8].The malignant variant of CS is rare. In most cases of MCS, anaplastic changes are present from the beginning. Malignant chondroid syringoma is a mixed cutaneous tumor, with epithelial and mesenchymal components, which compromises principally the trunk and extremities. Rarely, a chondroid syringoma of many years duration suddenly undergoes malignant changes with widespread metastasis. [9] There have been no reports reporting effectiveness of chemotherapy and radiotherapy, and an early wide excision with a broad margin may be the most reliable treatment to date. In this paper, we present a case of MCS localized in anterior abdominal wall.

CASE REPORT: A 55-year-old female was admitted in 2010 at the Department of Surgery, Bankura Sammilani Medical College with a slowly growing nodular lesion at the anterior abdominal wall. The lesion was a painless, slow growing nodular lesion gradually increasing in size for last five years. On 
physical examination, the solitary, dome-shaped, skin-coloured, and firm nodule, measuring $35 \mathrm{~mm}$ x $35 \mathrm{~mm}$, was noted in the anterior abdominal wall $5 \mathrm{~cm}$ above and lateral to the umbilicus. The tumor was not adhered to the rectus sheath. The FNAC from the lesion was inconclusive. The nodule was surgically removed along with a $1 \mathrm{~cm}$ margin and the defect was closed after mobilization of residual skin. The surgical specimen showed a lobular proliferation of tumor cells with glandular differentiation associated with a few mitotic cells, embedded in a mucinous stroma (Figures 1). Immunohistochemistry showed that the majority of tumor cells were positive for PAS diastase, toluidine blue, cytokeratin (CAM5.2, CK7), S-100 protein, and GCDFP-15. From the above findings, a diagnosis of chondroid syringoma was made. Surgical margins were negative. Ultrasound of the regional lymph nodes and radiography of the chest and abdomen showed no evidence of metastasis. The patient, who has been disease-free for three years following surgery, is still under follow up every three months for any recurrence.

DISCUSSION: Chondroid syringomas are tumors arising from sebaceous glands, sweat glands, and ectopic salivary glands. ${ }^{[10]}$ They usually present with slow-growing, painless, solid, subcutaneous or intradermal nodules with a normal margin. They account for $<0.01 \%$ of all primary skin tumours. They most commonly occur in the head and neck of adult males, followed by nose, cheeks, upper lip, scalp, forehead and chin. Tumour size may range from $2 \mathrm{~mm}$ to $\geq 1 \mathrm{~cm}$. ${ }^{[5-8]}$ The lesion is usually solitary with a benign nature. However, very rare malignant cases were also reported. Analysis of the reported cases showed that the mean age of the patients at the time of diagnosis was 48.3 years (range 13-84 years). The neoplasm has a preponderance to affect limbs mostly (61\% in limbs, 17\% in trunk, and $22 \%$ in head and neck), while its benign counterpart affect mainly in the head and neck ( $80 \%$ in head and neck, $10 \%$ in limbs, and 10\% in trunk). [11,12] The female-to-male ratios are 3: 2 in MCS and 2: 7 in its benign counterpart. [11] In our case, the patient had a history of a slowly growing lesion at the anterior abdominal wall which slowly progressed over a period of 5 years. Malignant chondroid syringoma may be present de novo or rarely develop in a chondroid syringoma. In contrast to the benign counterpart, which is common in the head and neck region, the malignant variety occurs predominantly on the trunk and extremities. [13-15] In our patient, a middle-aged woman, the tumour was on anterior abdominal wall. The female preponderance of this tumour is reported in many studies. [14-17] In our case also, prior studies that had mitosis, nuclear atypia, pleomorphism, lymphatic invasion have been recognized as helpful signs for the diagnosis of malignancy $[9,14-16,18]$. Chondroid syringoma may be confused clinically with epidermal cyst, pilar cyst, calcifying epithelioma, or a solitary trichoepithelioma. [19]

In our case, the tumor initially could not be properly diagnosed with FNAC. The definitive diagnosis was based on the wide excision of the tumour which is also the treatment of choice. Though local radiotherapy is often unsuccessful, skeletal metastasis has been shown to respond to radiotherapy. [16] Combination chemotherapy in patients with metastasis is not reported to be beneficial. [16] Adequate surgical excision with wide disease-free margins is the only hope for disease control. [14, 16, 20] Our case has been defined as disease-free for three years following wide excision. In terms of prognosis of the reported cases, 8 of the 30 (27\%) patients died from their disease. Death occurred as early as 9 weeks following surgery; one patient survived 12 years after diagnosis. [10, 21] Malignant chondroid syringoma tends to follow an unpredictable clinical course with recurrence occurring within first year. [23] Of the reported cases, 50\% had local recurrences. [20-22] Nodal 


\section{CASE REPORT}

metastases and distant metastases were observed in $39 \%$ and $36 \%$ of the cases, respectively. The most common site for distance metastasis was lung, followed by bone and brain. [20, 24] In conclusion, negative surgical margin should be attained using wide excision technique. These patients should be also monitored closely due to high potential of recurrence.

CONCLUSIONS: Malignant chondroid syringoma tends to appear between $4^{\text {th }}$ to $5^{\text {th }}$ decades of life and follow an unpredictable clinical course. The neoplasm has a preponderance to affect limbs mostly (61\%), while its benign counterpart affect mainly in the head and neck (80\%). Diagnosis was based on the wide surgical excision of the tumour. Combination chemotherapy in patients with metastasis is not reported to be beneficial. In conclusion, negative surgical margin should be attained using wide excision technique. These patients should be also monitored closely due to high potential of recurrence.

\section{REFERENCES:}

1. W. F. Lever, "Schaumburg-lever G. tumors of the epidermal appendages," in Histopathology of the Skin, pp. 560-562, J. B. Lippincott, Philadelphia, Pa, USA, 6th edition, 1983.

2. A. H. Chen, E. H. Moreno, B. Houston, and G. F. Funk, "Chondroid syringoma of the head and neck: clinical management and literature review," Ear, Nose and Throat Journal, vol. 75, no. 2, pp. 104-108, 1996.

3. P. Hirsch and E. B. Helwig, "Chondroid syringoma-mixed tumor of skin, salivary gland type," Archives of dermatology, vol. 84, pp. 835-847, 1961.

4. J. T. Headington, "Mixed tumors of skin: eccrine and apocrine types," Archives of dermatology, vol. 84, pp. 989-996, 1961.

5. A. Obaidat, K. O. Alsaad, and D. Ghazarian, "Skin adnexal neoplasms-part 2: an approach to tumours of cutaneous sweat glands," Journal of Clinical Pathology, vol. 60, no. 2, pp. 145-159, 2007.

6. R. Sivamani, A. Wadhera, and E. Craig, "Chondroid syringoma: case report and review of the literature," Dermatology Online Journal, vol. 12, no. 5, article no. 8, 2006.

7. J. W. Poku, G. R. Sant, and A. A. Ucci, "Chondroid syringoma of the scrotum," Journal of International Medical Research, vol. 24, no. 6, pp. 482-486, 1996.

8. S. Sheikh, M. Pennanen, and E. Montgomery, "Benign chondroid syringoma: report of a case clinically mimicking a malignant neoplasm,” Journal of Surgical Oncology, vol. 73, pp. 228230, 2000.

9. D. Elder, R. Elenitsas, and B. D. Ragsdale, "Tumors of the epidermal appendages," in Lever's Histopathology of the Skin, D. Elder, Ed., pp. 747-804, Lippincott-Raven, New York, NY, USA, 1997.

10. R. A. Mathiasen, B. M. Rasgon, and G. Rumore, "Malignant chondroid syringoma of the face: a first reported case," Otolaryngology, vol. 133, no. 2, pp. 305-307, 2005.

11. P. Hirsch and E. B. Helwig, "Chondroid syringoma. Mixed tumor of skin, salivary gland type," Archives of dermatology, vol. 84, pp. 835-847, 1961.

12. A. P. Stout and J. G. Gorman, "Mixed tumors of the skin of the salivary gland type," Cancer, vol. 12, pp. 537-543, 1959. 
13. M.D. Barnett, M. K. Wallack, A. Zuretti, L. Mesia, R. S. Emery, and A. M. Berson, "Recurrent malignant chondroid syringoma of the foot: a case report and review of the literature," American Journal of Clinical Oncology, vol. 23, no. 3, pp. 227-232, 2000.

14. P. Shashikala, H. R. Chandrashekhar, S. Sharma, and K. K. Suresh, "Malignant chondroid syringoma," Indian Journal of Dermatology, Venereology and Leprology, vol. 70, no. 3, pp. 175-176, 2004.

15. J. C. Steinmetz, B. A. Russo, and R. E. Ginsburg, "Malignant chondroid syringoma with widespread metastasis," Journal of the American Academy of Dermatology, vol. 22, no. 5 I, pp. 845-847, 1990.

16. V.Seenu, A. K. Goel, N. K. Shukla, M. B. Prakash, and R. Mohan, "Malignant chondroid syringoma of scalp with cervical lymph node metastases," Journal of Association of Physicians of India, vol. 44, no. 8, pp. 565-566, 1996.

17. C. Redono, A. Rocamora, F. Villoria, and M. Garcia, "Malignant mixed tumor of the skin: malignant chondroid syringoma," Cancer, vol. 49, no. 8, pp. 1690-1696, 1982.

18. E. Ishimura, H. Iwamoto, and Y. Kobashi, "Malignant chondroid syringoma. Report of a case with widespread metastasis and review of pertinent literature," Cancer, vol. 52, no. 10, pp. 1966-1973, 1983.

19. H. R. Jerajani and S. T. Amladi, "Skin tumors and lymphoproliferative disorders," in IADVL Textbook and Atlas of Dermatology, R. G. Valia and A. R. Valia, Eds., pp. 1149-1244, Bhalani, Mumbai, India, 2001.

20. H. Takahashi, A. Ishiko, M. Kobayashi, A. Tanikawa, H. Takasu, and M. Tanaka, "Malignant chondroid syringoma with bone invasion: a case report and review of the literature," American Journal of Dermatopathology, vol. 26, no. 5, pp. 403-406, 2004.

21. A. Watarai, Y. Amoh, R. Aki, H. Takasu, and K. Katsuoka, "report of a case with lymph node metastasis 12 years after local excision," Dermatology Online Journal, vol. 17, article 5, 2011.

22. K. Nemoto, N. Kato, and H. Arino, "Chondroid syringoma of the hand," Scandinavian Journal of Plastic and Reconstructive Surgery and Hand Surgery, vol. 36, no. 6, pp. 379-381, 2002.

23. Deniz Tural, Fatih Selçukbiricik, Feray Günver, Abdülkadir Karışmaz, and Süheyla Serdengecti, "Facial Localization of Malignant Chondroid Syringoma: A Rare Case Report," Case Reports in Oncological Medicine, vol. 2013, Article ID 907980, 3 pages, 2013.

24. J. L. Araújo, G. B. de Aguiar, U. do Prado Aguiar, D. Mayrink, N. Saade, and J. C. Veiga, "Malignant chondroid syringoma with central nervous system involvement," Journal of Craniofacial Surgery, vol. 23, pp. 514-515, 2012. 
LEGEND : Fig 1: Histopathological examination of excised mass. Tumour showed a lobular proliferation of tumour cells with glandular differentiation associated with anaplastic changes and mitotic cells, in the background of a mucinous stroma. In addition, generalized lymph vascular invasion was present $(\mathrm{HE}, \times 200)$.

Fig. 1

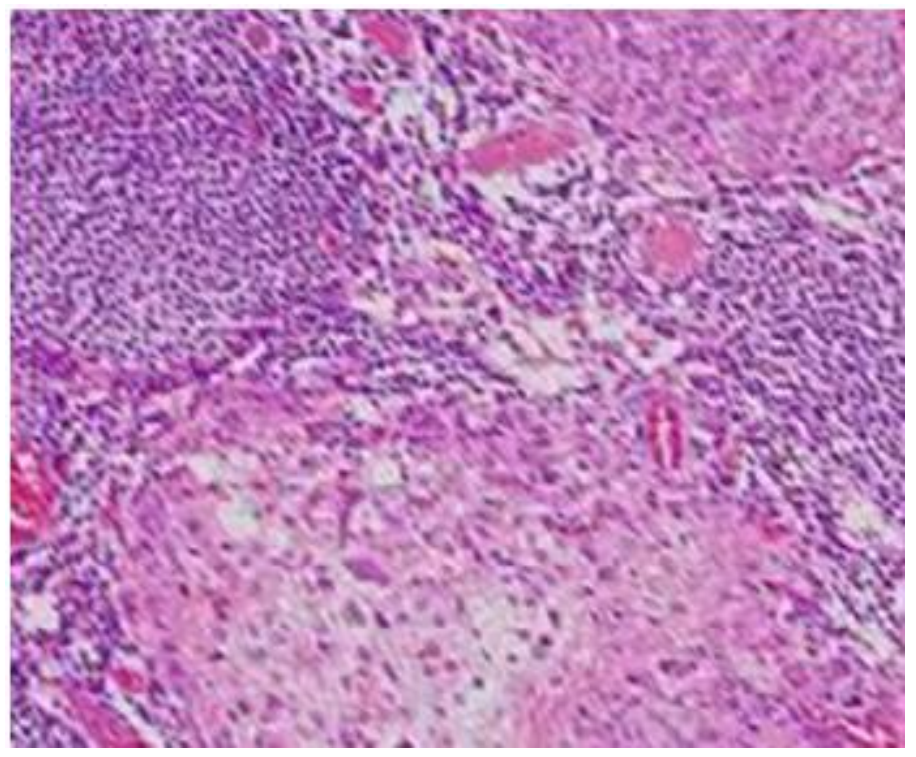

\section{AUTHORS:}

1. Ram Krishna Mondal

2. Santanu Acharyya

3. Debkumar Ray

4. Sumitava De

\section{PARTICULARS OF CONTRIBUTORS:}

1. Associate Professor, Department of Surgery, B.S. Medical College, Bankura, WB.

2. Assistant Professor, Department of Radiotherapy, B.S. Medical College, Bankura, WB.

3. Assistant Professor, Department of Biochemistry, B.S. Medical College, Bankura, WB.
4. RMO cum Clinical Tutor, Department of Radiotherapy, B.S. Medical College, Bankura, WB.

\section{NAME ADRRESS EMAIL ID OF THE CORRESPONDING AUTHOR:}

Dr. Debkumar Ray,

KL-1, Jagatpur, Ganga Yamuna Apt, Block-B, Flat No.: C \& D, Kolkata -700059, Email:dr.debkumar@gmail.com

Date of Submission: 29/06/2013. Date of Peer Review: 01/07/2013. Date of Acceptance: 08/07/2013. Date of Publishing: 19/07/2013 